\title{
Topographic and Morphometric Study on the Kidneys of Balady Rabbit Enhanced by Ultrasonographic, Radiographic and Computed Tomography Scan
}

\author{
Hanaa M. EL-Ghazali ${ }^{*}$, Saeed Mohammed Saleh Ammar ${ }^{1}$, Sherif Kh. A. Mohamed ${ }^{1}$, Mohamed \\ Gomaa $^{2}$ and Sahar Mohamed El-Sayed Ibrahim ${ }^{1}$
}

${ }^{1}$ Department of Anatomy and Embryology, Faculty of Veterinary Medicine, Zagazig University, 44511, Egypt.

${ }^{2}$ Department of Surgery, Anesthesiology and Radiology, Faculty of Veterinary Medicine, Zagazig University, 44511, Egypt.

*Corresponding author: dr_h1980@hotmail.com; hmelghazali@zu.edu.eg

Article History: 21-278 Received: 09-Feb-21 Revised: 22-May-21 Accepted: 13-Jun-21
A BS TRA C T
The aim of this work is to throw more light on using some recent techniques as ultrasound, computed tomography (CT),
and contrast radiography in examination of the kidney of Balady rabbit. The current work was carried out on 23 adult
healthy Balady rabbits. Topographical, morphometrical and radiographical examination on kidneys were occurred.
Ultrasonographically, the animal was examined in both dorsal and lateral recumbency. Both kidneys were scanned in
longitudinal and transverse planes. The different ultrasonographic measurements of both kidneyswere recorded.The
rabbit was positioned in ventral recumbency and CT images were taken without contrast medium using multi-slices CT
system. The right kidney was slightly anterior to the level of left one by its length. The right lobe of liver separated the
right kidney from the stomach cranially. The left kidney was separated from the stomach and spleen with the ascending
duodenum and jejunum. By contrast radiographs, both kidneys appeared clearly as dense soft tissues with distinct borders
against the neighboring vertebrae and ribs. In the longitudinal ultrasonographic scanning plane, the medulla revealed
anechoic nearly circular areas represented the peri-pelvic columns which separated by hyperechoic secondary septa. The
main pelvic septum appeared hyperechoic. We could easily distinguish between the cortex and medulla in both
longitudinal and transverse scanning plane. Therefore, we hope to contribute to clinic and histopathological diagnosis of
kidney diseases.

Keywords: Kidneys, Cortex, Medulla, Ultrasonographic, Computed tomography (CT) scan, X-ray, Echogenicity

\section{INTRODUCTION}

The rabbit is considered as a suitable experimental model for research of kidney transplantations in human (Wu et al. 2003) and one of the most widely distributed animal species used in economical purposes and laboratory studies. Recently, it is kept as pets (Hristov et al. 2006). The rabbit is a good biological model for clinical and anatomical study of the kidney lesions in animals (Dimitrov et al. 2012). There are many authors dealt with the kidneys of experimental animals as Dorotea et al. (2016a) in domestic rat, Makungu et al. (2016), Mazensky and Flesarova (2017) in guinea pig, Thrall (2017) and Al-Kelaby et al. (2018) in rabbits and (Sánchez-Solís et al. 2018, Souza et al. 2018; Dal Monte et al. 2019) in rats.

Ultrasonography allows imaging of the internal parenchyma of the organ and differentiating between fluid and soft tissues (Redrobe 2001). Ultrasonographic examination of the urinary tract is commonly used in veterinary medicine (Mantis 2008). The survey radiography and ultrasonography of the abdominal cavity are considered as complementary tools for examination of the rabbit diseases (Redrobe 2013). As Doppler ultrasound equipment examination is being widespread and quantitative analysis of the intrarenal arteries, it has been quickly extrapolated to veterinary medicine (Ostrowska et al. 2016).

Recently, there is an increase in the use of computed tomography (CT) of the body cavities as an important and useful imaging modality in veterinary medicine as it can provide high-detail images of the thorax and abdomen (Samii et al. 1998). Computed tomography (CT) is a most valuable technique used for the diagnosis of abdominal diseases and has become the imaging method of choice for the abdomen in the human medicine (El Sherif et al. 1999; Novelline et al. 1999; Ibrahim et al. 2019).

Cite This Article as: EL-Ghazali HM, Ammar SMS, Mohamed SKA, Gomaa M and Ibrahim SME, 2022. Topographic and morphometric study on the kidneys of Balady rabbit enhanced by ultrasonographic, radiographic and computed tomography scan. International Journal of Veterinary Science 11(1): 28-36. https://doi.org/10.47278/journal.ijvs/2021.072 
In veterinary medicine, however, $\mathrm{x}$-ray and ultrasound are the imaging methods of choice for the abdomen but computed tomography (CT) can provide information that cannot be obtained by other methods (Gavrilas et al. 2016). This is due to a better differentiation between the different CT tissue densities in the abdominal cavity (Fike et al. 1980; Stickle and Hathcock 1993). Some authors such as Moarabi et al. (2011), Dimitrov (2012), Redrobe (2013) and Banzato et al. (2014a) studied the sonographic features of the rabbit kidneys, but there are no comprehensive studies dealt with the radiographic examination and computed tomography. So, the aim of this work is to throw more light on using some recent techniques as ultrasound, computed tomography (CT) and contrast radiography in examination of the kidney of Balady rabbit. Therefore, we hope to contribute to clinic and histopathological diagnosis of kidney diseases.

\section{MATERIALS AND METHODS}

The current work was carried out on 23adult healthy Balady rabbits of both sexes with variable ages and were weighted $2-3.5 \mathrm{~kg}$. The animals were collected from villages of Zagazig, Sharkia, Egypt. All animals managed according to Animal Ethical Committee of Faculty of Veterinary Medicine, Zagazig University, Egypt.

\section{Topographical and Morphometrical Examination}

In this study, 10 rabbits were slaughtered humanely, and their thoracic cavities were opened then injected with $10 \%$ formalin solution (10\% formalin, $3 \%$ glycerin and $1 \%$ thymol) through the thoracic aorta. The injected specimens were preserved in the same formalin solution with intact abdomen for two weeks till complete fixation of organs. The abdomen of fixed rabbits was opened ventrally and laterally with removal of the abdominal muscles and dissected for detection of position and relations of each kidney with adjacent organs inside the abdominal cavity. The specimens were photographed by a digital camera with resolution (16.1megapixels, Sony DSC-W690, 36V and 10x optical zoom). After removal of the kidneys from their position, the different measurements of the kidneys were obtained. The length and width of the kidneys were estimated by using a graduated tape, while the weight was obtained by using a digital scale.

\section{Gray scale Ultrasonographic Examination}

Five rabbits were sedated with a mixture of Ketamine HCL (35mg/kg bwt) and Xylazine (5mg/kg bwt) injected im (Lin 2007). The hair on the abdomen was shaved from the sternum to the pubis wide enough on left and right sides and applied enough acoustic gel. The animal was examined in both dorsal and lateral recumbency for obtaining a complete scanning of the right and left kidneys and their relations with the adjacent organs. Both kidneys were scanned in longitudinal and transverse planes. The different ultrasonographic measurements of both kidneys including the length measured from the cranial to caudal poles of the kidney (in the longitudinal scanning plane), the width measured from lateral to medial borders of the kidney (in the transverse scanning plane) and the depth measured from dorsal to ventral surfaces of the kidney (in the transverse and longitudinal scanning plane) were recorded. The echogenicity of the different parts of the kidney comparing with the adjacent organs was determined.

The gray scale ultrasound examination was performed at Department of Surgery, Anesthesiology and Radiology and Department of Obstetrics and Gynecology, Faculty of Veterinary Medicine, Zagazig University, Egypt. The images were taken with a linear probe (frequency 4-9MHz) connected to ultrasound equipment: SonoScape A5v and Esaote MyLab (Nither Land).

\section{Radiographic Examination}

After sedation and anesthesia with the previous mixture of Ketamine HCL and Xylazine solution, five rabbits were injected with non-ionic contrast medium, iohexol injection $76 \%$ (Omnipaque $囚 350$ ), 350mg/mL, $3 \mathrm{~mL} / \mathrm{kg}$ bwt (GE Healthcare, Ireland), in the blood stream through the retro-auricular vein (Dimitrov and Chaprazov 2012). Lateral and ventro-dorsal radiographic views were taken, before and after administration of the contrast medium, every five minutes until the contrast medium completely excreted for detection the position of both kidneys in relation to the vertebrae and the adjacent organs. The examination was performed at Dr. Khaled Abdul Aziz Sonoscan center in Zagazig, Sharkia Governorate using the digital diagnostic X-ray machine DRGEM, made in Korea with exposure factors $60-65 \mathrm{KV}$, 320MA and 17MAs. Within five minutes from injection the contrast medium, both kidneys began to appear clearly with distinct borders against the surrounding structures, but renal pelvis and ureter could not be observed.

Within ten minutes of injecting the contrast medium, the ureter and renal pelvis filled with the radiopaque contrast medium began to appear. Within fifteen minutes from injection of the contrast medium, we could observe the ureters and urinary bladder (Dimitrov and Chaprazov 2012).

\section{Computed Tomography Scan (CT)}

CT study was performed at AL-Bayan center in Belbes, Sharkia Governorate. Three rabbits were anesthetized with the previous mixture of Ketamine HCL and Xylazine solution. The rabbit was positioned in ventral recumbency, and CT images were taken without contrast medium using multi-slices CT system (Somatom Sensation 16) which can acquire up to 32 slices per second with fast whole-body scan time of 0.5 seconds, $50 \mathrm{~kW}$ X-Ray Generator, Multiple kV and $\mathrm{mA}$ techniques and 5.0MHU $\mathrm{X}$-Ray Tube. Series of $1 \mathrm{~mm}$-thick transverse slices were taken on the thorax and abdomen from the first rib till hip joint and scanning along the sagittal and dorsal (coronal) planes was also performed. Immediately after CT imaging, two rabbits were slaughtered and freezed at $-20^{\circ} \mathrm{C}$ in the same position as CT imaging (ventral recumbency). After freezing, the cadavers were sectioned into $2 \mathrm{~cm}$-thick transverse sections perpendicular on the longitudinal axis of rabbit trunk at spinous process of each vertebra from the last thoracic vertebra till fourth lumbar vertebra using an electric band saw and comparison between cross anatomic sections and CT transverse slices was obtained. The other rabbit was slaughtered and freezed at $-20^{\circ} \mathrm{C}$ in ventral 
recumbency then, was sectioned into right and left paramedian sagittal sections every $1 \mathrm{~cm}$ parallel to midline of rabbit trunk for studying relations of both kidneys (Fig.1). The anatomical nomenclature used in this study was based on Nomina Anatomica Veterinaria (2017), whenever possible.

\section{RESULTS}

The right kidney was slightly anterior to the level of left one by its length (Fig. 2A \& B). The right kidney (Ren dexter) extended from last thoracic to first lumbar vertebrae, was related dorsally to transverse processes of first and second lumbar vertebrae. The right kidney was related to the last two ribs laterally (Fig. 2, 3A \&B). The left kidney (Ren sinister) was not extended to thoracic cage as it was situated at the level of second and third lumbar vertebrae. It was related dorsally to transverse processes of second, third and fourth lumbar vertebrae (Fig. 2, 3A \& C).

By contrast radiographs, both kidneys appeared clearly as dense soft tissues with distinct borders against the neighboring vertebrae and ribs. The intestinal parts which were radiolucent structures appeared black due to gases. The left kidney was situated caudal to the right one in the dorsoventral view (Fig. 2B) and appeared caudoventrally to the right kidney in the lateral view (Fig. 3A). The renal parenchyma was distinguished into a higher opacity medulla than the cortex (Fig. 2B \& 3A). The renal pelvis and ureter began to be filled with the radiopaque contrast medium so the renal pelvis appeared as radiopaque finger like projections at the medial border in ventro-dorsal view (Fig. 2B) and at the center of the kidney in lateral view (Fig. 3A). The ureter could be detected as a white tube extended from renal pelvis caudally till the urinary bladder (Fig. 3A).

The descending duodenum passed ventral to right kidney and extended to its caudal extremity separating it from the descending and ascending colon in addition to cecum (Fig. 3B). The right lobe of liver separated the right kidney from the stomach cranially (Fig. 4A). The right kidney was related to the descending colon and cecum ventrally and caudoventrally and the duodenum with pancreas cranioventrally (Fig. 4 \& 5).

The right lateral and caudate lobes of the liver capped the right kidney cranioventrally under the last intercostal space forming a renal impression on their surface without hepatorenal ligament between them (Fig. 4A, 5A \& B). The right adrenal gland could be seen embedded in perirenal fat craniomedial to the right kidney (Fig. 5C \& D).

The sequence examination of the anatomic frozen cross sections, transverse and coronal CT images revealed, the kidneys were situated at upper part of the abdomen in lateral abdominal region to the right and left of the median plane. The right kidney firstly appeared followed by the left one in the contiguous anatomic cross sections and CT images (Fig. $5 \& 6 \mathrm{~A}$ ). The caudate lobe of the liver and the right kidney density were the same, but the perirenal fat could differentiate between them by its hypodensic image as it appeared dark gray between them (Fig. 4B, 5B \& 6A). Part of the rib appeared as a white structure with a higher tissue density bordered the right kidney laterally (Fig. 5B).

The caudal vena cava, adrenal gland, lateral abdominal wall and sublumbar muscles appeared gray as they had intermediate tissue density (Fig. 5B \& D). The intestinal parts appeared with different tissue densities as its wall appeared gray and the lumen was black due to the

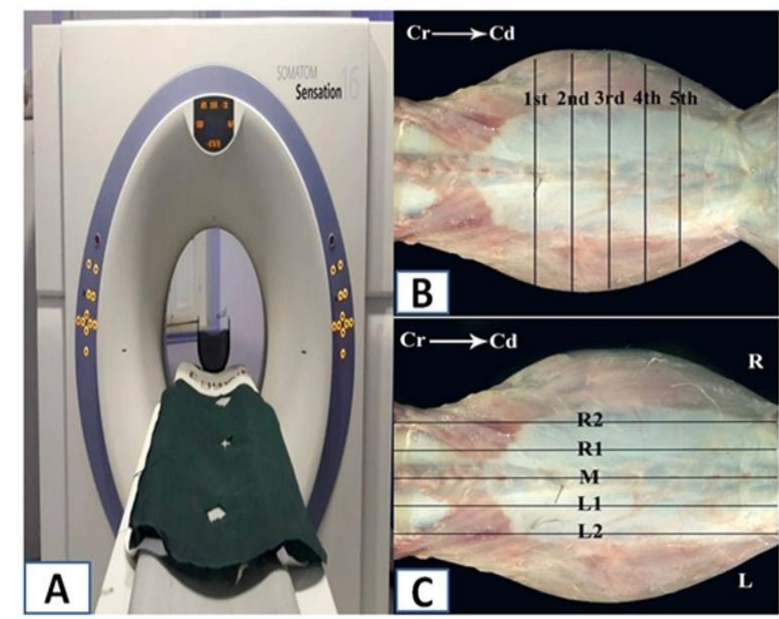

Fig. 1: A photomacrograph showing multi-slices CT system (Somatom Sensation 16) used in this study (A). A photomacrograph showing the range of frozen cross anatomical sections, every $2 \mathrm{~cm}$ perpendicular on the longitudinal axis of the trunk of rabbit from cranial to caudal (B). A photomacrograph showing the range of frozen paramedian anatomical sagittal sections, every $1 \mathrm{~cm}$ parallel to the midline of the trunk of rabbit (C) Showing first cross section at the last thoracic vertebra $\left(1^{\text {st }}\right)$, Second cross section at first lumbar vertebra $\left(2^{\text {nd }}\right)$, Third cross section at second lumbar vertebra $\left(3^{\text {rd }}\right)$, Fourth cross section at third lumbar vertebra $\left(4^{\text {th }}\right)$, Fifth cross section at fourth lumbar vertebra $\left(5^{\text {th }}\right)$, Midline sagittal section $(\mathrm{M})$, First right paramedian sagittal section (R1), Second right paramedian sagittal section (R2), First left paramedian sagittal section (L1), Second left paramedian sagittal section (L2), Right (R), Left (L), Cranial (Cr), Caudal (Cd).
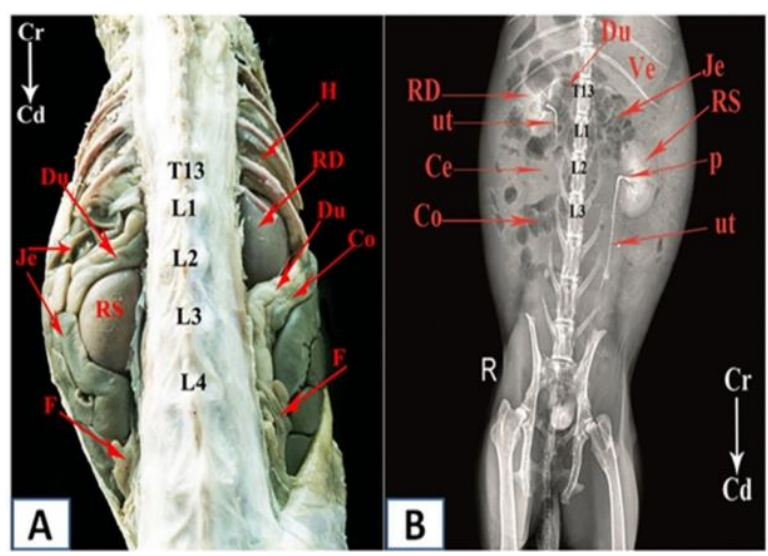

Fig. 2: A photomacrograph of rabbit showing position of both kidneys in relation to vertebrae (A). A contrast radiograph of rabbit showing position and relation of both kidneys (ventrodorsal view) (B) Showing: Ren dexter (RD), Ren sinister (RS), Duodenum (Du), Hepar (H), Uterus (F), Colon Descendens (Co), Cecum (Ce), Jejunum (Je), Ventriculus (Ve), Pelvis renalis (P), Ureter (ut), Thirteenth thoracic vertebra (T13), First lumbar vertebra (L1), Second lumbar vertebra (L2), Third lumbar vertebra (L3), Fourth lumbar vertebra (L4), Cranial (Cr), Caudal (Cd) and Right (R). 
presence of low CT density feces and gases (Fig. 5B, D \& 6A). The kidney by CT scan could be imaged as a homogenous soft tissue density and gray colored as it had an intermediate tissue density. There was no difference in the density between cortex and medulla (Fig. 6A).

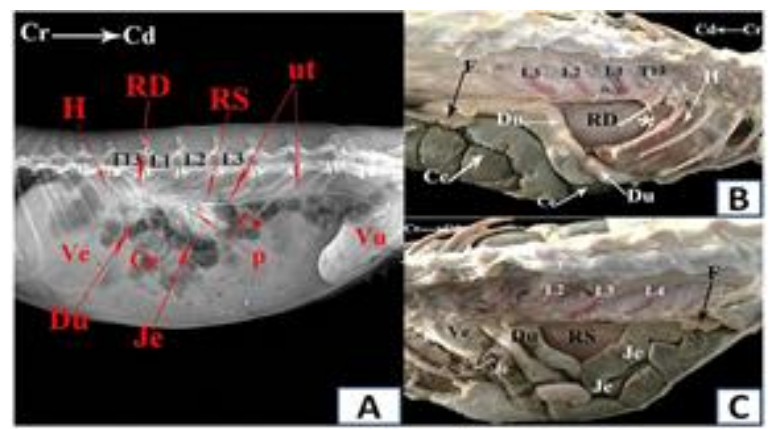

Fig. 3: A contrast radiograph of rabbit showing the position and relations of both kidneys (lateral view) (A). A photomacrograph of rabbit showing the position and relation of the right kidney (B). A photomacrograph of rabbit showing the position and relation of the left kidney (C)Showing: Ren dexter (RD), Ren sinister (RS), Duodenum (Du), Hepar $(\mathrm{H})$, Uterus (F), Colon Descendens (Co), Cecum (Ce), Jejunum (Je), Ventriculus (Ve), Pelvis renalis (P), Ureter (ut), Thirteenth thoracic vertebra (T13), First lumbar vertebra (L1), Second lumbar vertebra (L2), Third lumbar vertebra (L3), Fourth lumbar vertebra (L4), Cranial (Cr), Caudal $(\mathrm{Cd})$, Last intercostal space $\left(^{*}\right)$ and Vesica urinaria $(\mathrm{Vu})$.

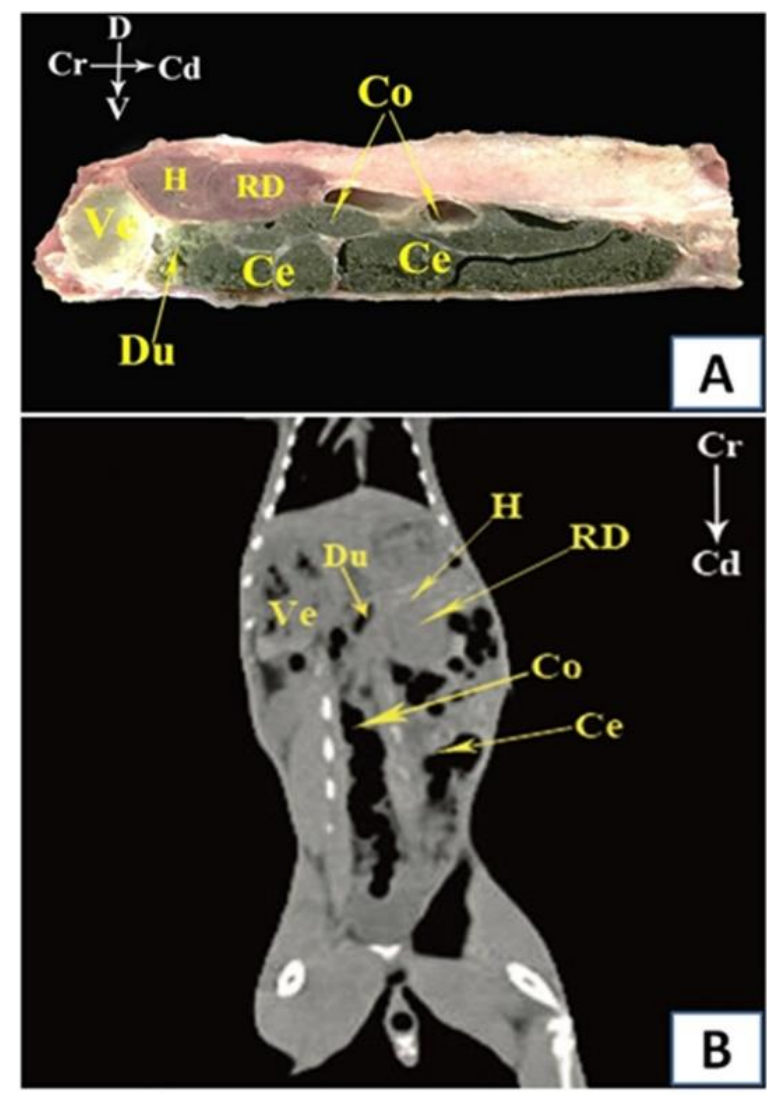

Fig. 4: A photomacrograph of the second right paramedian sagittal section showing the right kidney and its relations (A). Acoronal computed tomography (CT) scan of rabbit showing the right kidney and its relations (B) Showing Ren dexter (RD), Duodenum (Du), Ventriculus (Ve), Hepar (H), Colon descendens (Co), Cecum (Ce), Cranial (Cr), Caudal (Cd), Ventral (V) and Dorsal (D).
In the radiographic image, the renal hilus appeared as a central depression with low opacity on the middle of the medial border, as it contained fat with low density (Fig. 6B).

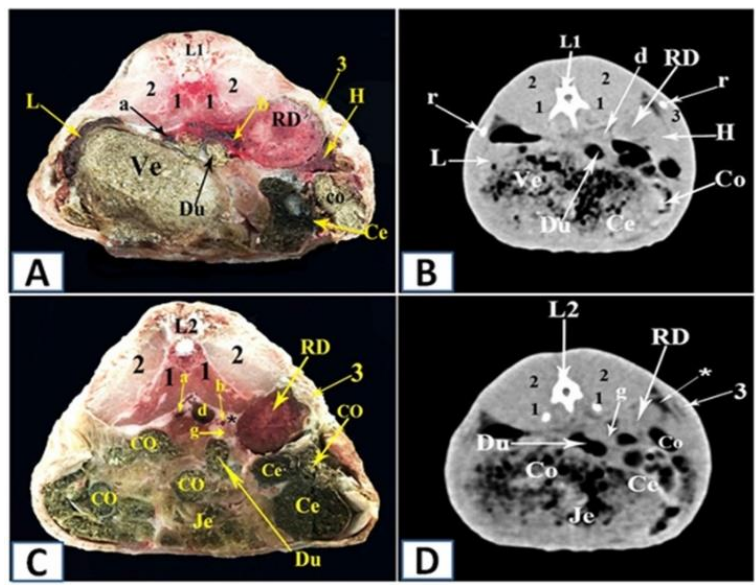

Fig. 5: A photomacrograph of the second frozen cross anatomical section showing the right kidney and its relation at the level of the first lumbar vertebra (A). A transverse computed tomography (CT) scan of rabbit at the level of the first lumbar vertebra (B). A photomacrograph of the third frozen cross anatomical section showing the right kidney and its relation at the level of the second lumbar vertebra (C). A transverse computed tomography (CT) scan of rabbit at the level of the second lumbar vertebra (D) Showing first lumbar vertebra (L1),Second lumbar vertebra (L2), Ren dexter (RD), Lien (L), Ventriculus (Ve), Duodenum (Du), Colon descendens (Co), Cecum (Ce), Hepar (H), Costa (r), Jejunum (Je),Sublumbar muscles (1), M. longissimus lumborum (2),Right lateral abdominal wall (3), Aorta abdominalis (a), Right renal vessels (b), Vena cava caudalis (d), Glandula adrenalis dexter (g) and Capsula adipose $(*)$.

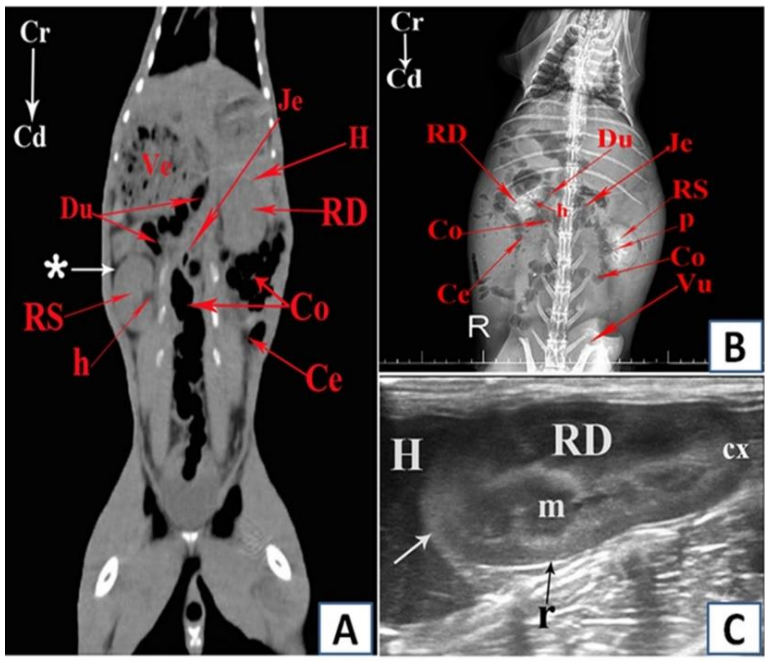

Fig. 6: Acoronal computed tomography (CT) scan of rabbit showing both kidneys and their relations (A). A contrast radiography of rabbit showing the relations of both kidneys (ventrodorsal view) (B). Ultrasonographic image of the right kidney in a longitudinal scanning plane related to the liver (dorsal recumbency). (C) Showing Ren dexter (RD), Ren sinister (RS), Cortex renis (cx), Medulla renis (m), Pelvis renalis (P), Hilus renalis (h), Renal capsule (r), Duodenum (Du), Hepar (H), Colon Descendens (Co), Cecum (Ce), Jejunum (Je), Ventriculus $(\mathrm{Ve})$, Impressio renalis (White arrow), Vesica urinaria $(\mathrm{Vu})$, Perirenal fat (*), Cranial (Cr) and Caudal (Cd). 


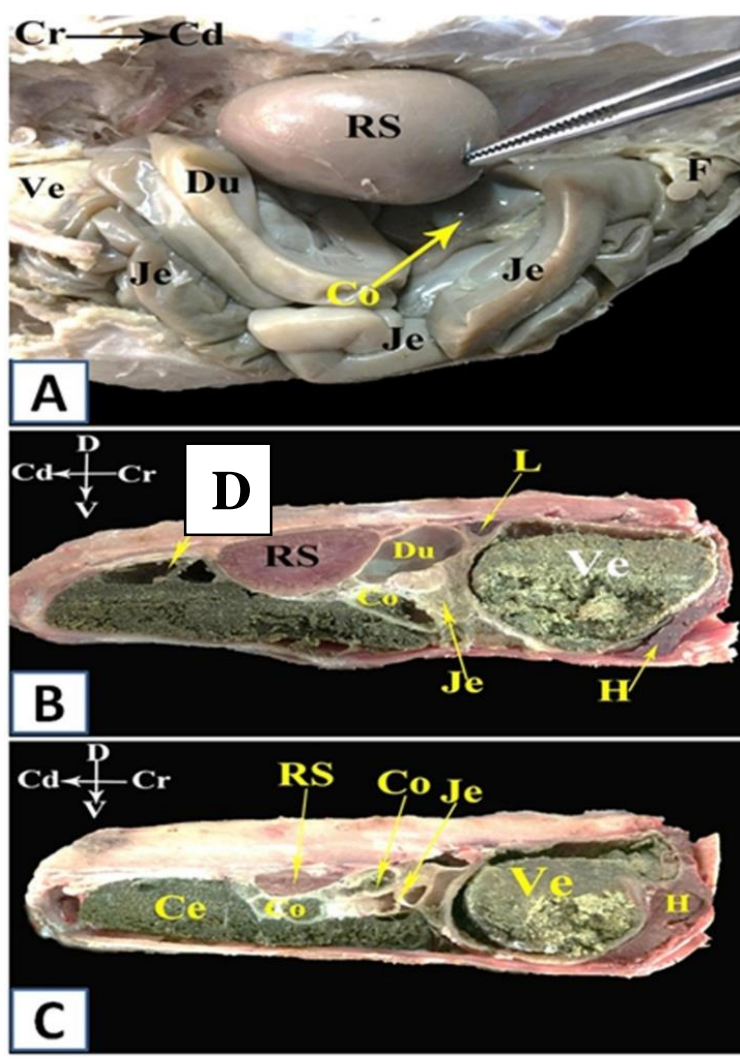

Fig. 7:A photomacrograph of rabbit showing the left kidney and its relation (A). Aphotomacrograph showing the first left paramedian sagittal section (B). Aphotomacrograph showing the second left paramedian sagittal section (C) Showing: Ren sinister (RS), Duodenum (Du), Ventriculus (Ve), Hepar (H), Colon descendens (Co), Cecum (Ce), Jejunum (Je), Uterus (F), Lien (L), Cranial (Cr), Caudal (Cd), Ventral (V) and Dorsal (D).



A

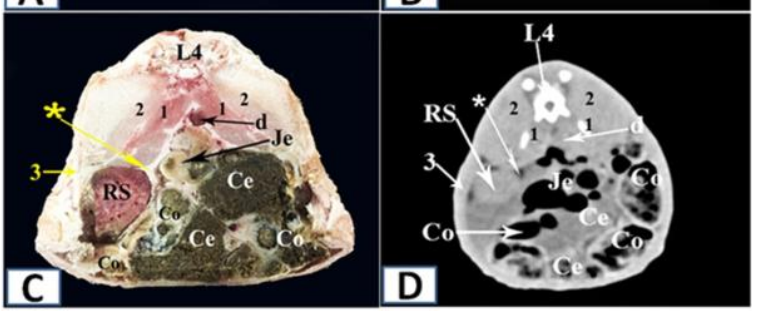

Fig. 8: A photomacrograph of the fourth frozen cross anatomical section showing the left kidney and its relation at the level of third lumbar vertebra (A). A transverse computed tomography (CT) scan of rabbit at the level of third lumbar vertebra (B). A photomacrograph of the fifth frozen cross anatomical section showing the left kidney and its relation at the level of fourth lumbar vertebra (C). A transverse computed tomography (CT) scan of rabbit at the level of fourth lumbar vertebra (D).Showing:Third lumbar vertebra (L3),Fourth lumbar vertebra (L4), Ren sinister (RS), hilus renalis (h), Duodenum (Du), Colon descendens (Co), Cecum (Ce), Jejunum (Je), Sublumbar muscles (1), M. longissimus lumborum (2), Left lateral abdominal wall (3), Vena cava caudalis (d), Glandula adrenalis sinister (g) and Capsula adipose $(*)$.

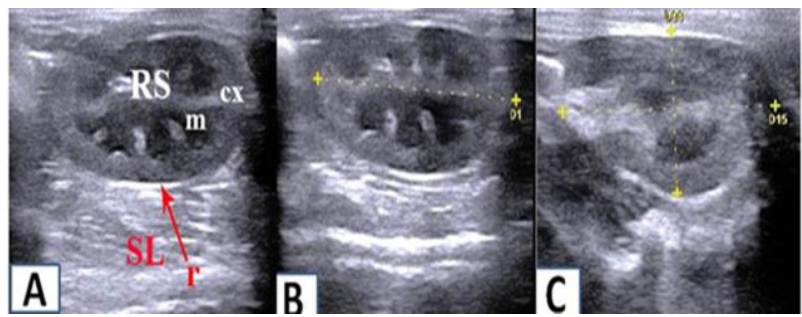

Fig. 9: Ultrasonographic image of the left kidney in a longitudinal scanning plane related with sublumbar muscles (dorsal recumbency) (A). Ultrasonographic image of the kidney in a longitudinal scanning plane showing the length of the kidney from cranial to caudal pole (dorsal recumbency) (B). Ultrasonographic image of the kidney in a transverse scanning plane showing the kidney width from medial to lateral border and the kidney depth from dorsal to ventral surface (dorsal recumbency) (C)Showing: Ren sinister (RS), Cortex renis (cx), Medulla renis (m), Length of the kidney (D1), Depth of the kidney (D14), Width of the kidney (D15), Renal capsule (r) and Sublumbar muscles (SL).
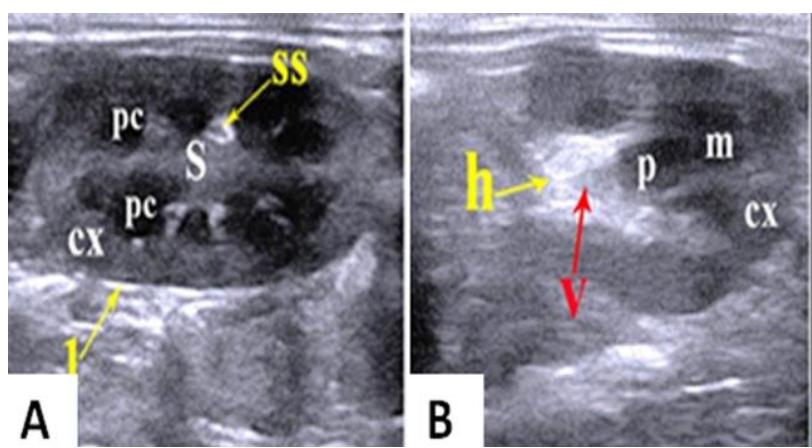

Fig. 10: Ultrasonographic image of the rabbit kidney in a longitudinal scanning plane showing the internal structure of the renal parenchyma (A). Ultrasonographic image of the rabbit kidney in a transverse scanning plane showing its internal structure (B). Showing: Cortex renis (cx), Medulla renis (m), Hilus renalis $(\mathrm{h})$, Papilla renalis $(\mathrm{P})$, Main septum of the rena pelvis (S), Secondary septa (ss), Peripelvic columns (pc), Pelvis renalis (V), Renal capsule (1)

The cranial contact of the right kidney with liver allowed the comparison between their echogenicity in the ultrasonographic image. Moreover, the liver appeared similar in echogenicity or slightly more than that of the renal cortex (Fig. 6C).

The left kidney was bordered ventrally with jejunum and the ascending duodenum cranioventrally. The descending colon was related to the left kidney ventrocaudally in between the jejunum (Fig. 6A, B, 7 \& $8)$. The left kidney was separated from the stomach and spleen with the ascending duodenum and jejunum (Fig. 7A \& B). The colon and jejunum separated between the left kidney and cecum (Fig. 7C \& 8). The left adrenal gland was situated in the perirenal fat craniomedial to the le ft kidney (Fig. 8A \& 8B).

The intestinal parts seemed hyperechoic than the kidney as they contained gases which considered a highly attenuating surface so, appeared white. The kidney was related dorsally to sublumbar muscles which appeared as hypoechoic striated bundles (Fig. 9A). The rabbit kidney appeared oval or nearly circular in outline by the longitudinal or transverse ultrasonographic scanning plane, respectively (Fig. 9B \& C). 
Int J Vet Sci, 2022, 11(1): 28-36

Table 1: Total rabbits divided according to the method of examination

Method of study

Topographical morphology and morphometrical examination.

Number of rabbits

Gray scale ultrasonographic examination.

Radiographic examination.

Computed Tomography scan (CT).

Five

Five

Three

Table 2: Different measurements of both kidneys in examined rabbits:

\begin{tabular}{|c|c|c|c|c|c|c|c|c|c|c|}
\hline \multirow{2}{*}{ Number of } & & \multirow[t]{2}{*}{ Sex } & \multirow{2}{*}{$\begin{array}{c}\text { Rabbit's age/ } \\
\text { months }\end{array}$} & \multirow{2}{*}{$\begin{array}{c}\text { Rabbit's } \\
\text { weight } / \mathrm{kg}\end{array}$} & \multicolumn{2}{|c|}{ Kidney's weight/g } & \multicolumn{2}{|c|}{ Kidney's length/cm } & \multicolumn{2}{|c|}{ Kidney's width/cm } \\
\hline & & & & & Right & Left & Right & Left & Right & Left \\
\hline rabbits & $1^{\text {st }}$ & Female & 9 & 3 & 5 & 5 & 3 & 3.2 & 2.1 & 2 \\
\hline \multirow[t]{9}{*}{ (No.) } & $2^{\text {nd }}$ & Male & 9 & 3.25 & 5 & 5 & 3.5 & 3.7 & 2 & 2 \\
\hline & $3^{\text {rd }}$ & Female & 11 & 2.9 & 5 & 5 & 3 & 3 & 1.9 & 2.1 \\
\hline & $4^{\text {th }}$ & Female & 12 & 3.5 & 10 & 10 & 4 & 4 & 2.7 & 2.5 \\
\hline & $5^{\text {th }}$ & Male & 12 & 3 & 5 & 5 & 3 & 2.8 & 2 & 1.8 \\
\hline & $6^{\text {th }}$ & Male & 10 & 2.25 & 5 & 5 & 3.2 & 3.4 & 2.3 & 2.5 \\
\hline & $7^{\text {th }}$ & Female & 10 & 3.1 & 10 & 10 & 3.3 & 3.5 & 2.3 & 2.5 \\
\hline & $8^{\text {th }}$ & Female & 11 & 3.5 & 10 & 10 & 4 & 4.1 & 2.2 & 2.4 \\
\hline & $9^{\text {th }}$ & Female & 12 & 3.1 & 10 & 10 & 3.9 & 4 & 2.4 & 2.5 \\
\hline & $10^{\text {th }}$ & Female & 10 & 3.25 & 10 & 10 & 3.9 & 3.8 & 2.8 & 2.7 \\
\hline Mean \pm SD & & & & & $7.5 \pm 2.6$ & $7.5 \pm 2.6$ & $3.48 \pm 0.43$ & $3.55 \pm 0.44$ & $2.27 \pm 0.29$ & $2.3 \pm 0.29$ \\
\hline
\end{tabular}

Table 3: Different ultrsonographic measurements of both kidneys in examined rabbits:

\begin{tabular}{|c|c|c|c|c|c|c|c|c|c|c|}
\hline \multirow{2}{*}{ Number of } & & \multirow[t]{2}{*}{ Sex } & \multirow[t]{2}{*}{$\begin{array}{c}\text { Rabbit's } \\
\text { age/ months }\end{array}$} & \multirow[t]{2}{*}{$\begin{array}{c}\text { Rabbit's } \\
\text { weight/kg }\end{array}$} & \multicolumn{2}{|c|}{ Kidney's depth/cm } & \multicolumn{2}{|c|}{ Kidney's length/cm } & \multicolumn{2}{|c|}{ Kidney's width/cm } \\
\hline & & & & & Right & Left & Right & Left & Right & Left \\
\hline rabbits & $1^{\mathrm{st}}$ & Female & 12 & 3.25 & 2 & 1.9 & 2.9 & 3.4 & 2.1 & 2.1 \\
\hline (No.) & $2^{\text {nd }}$ & Male & 11 & 2.9 & 1.7 & 1.8 & 3.6 & 3.5 & 2.8 & 2.1 \\
\hline & $3^{\text {rd }}$ & Female & 9 & 2.26 & 2 & 2.2 & 3.6 & 3.8 & 2.5 & 2.1 \\
\hline & $4^{\text {th }}$ & Female & 10 & 3.25 & 1.9 & 1.9 & 3.8 & 3.9 & 2.9 & 2.5 \\
\hline Mean \pm SD & $5^{\text {th }}$ & Male & 9 & 3.1 & $\begin{array}{c}1.9 \\
1.9 \pm 0.12\end{array}$ & $\begin{array}{c}1.8 \\
1.92 \pm 0.16\end{array}$ & $\begin{array}{c}3.7 \\
3.52 \pm 0.35\end{array}$ & $\begin{array}{c}3.8 \\
3.68 \pm 0.21\end{array}$ & $\begin{array}{c}2 \\
2.46 \pm 0.40\end{array}$ & $\begin{array}{c}2.4 \\
2.24 \pm 0.19\end{array}$ \\
\hline
\end{tabular}

The mean length of the right and left kidneys was $3.48 \pm 0.43$ and $3.55 \pm 0.44 \mathrm{~cm}$, respectively, while their mean width was $2.27 \pm 0.29$ and $2.3 \pm 0.29 \mathrm{~cm}$, respectively. The mean weight of both kidneys was about $7.5 \pm 2.6 \mathrm{~g}$ (Table 2). The ultrasonographic measurements revealed the mean length of the right kidney was $3.52 \pm 0.35 \mathrm{~cm}$ and of the left one was $3.68 \pm 0.21 \mathrm{~cm}$ (Fig.9B), while the mean width of the right kidney was $2.46 \pm 0.40 \mathrm{~cm}$ and of the left one was $2.24 \pm 0.19 \mathrm{~cm}$. The mean depth of the right and left kidneys was $1.9 \pm 0.12$ and $1.92 \pm 0.16 \mathrm{~cm}$, respectively (Fig.9C \& Table 3).

In the longitudinal ultrasonographic scanning plane, the medulla revealed anechoic nearly circular areas represented the peri-pelvic columns. The later separated from each other by hyperechoic secondary septa. The main pelvic septum in the central area of the kidney appeared hyperechoic than the surrounding cortex and medulla. The kidney was surrounded by the renal capsule which appeared as a regular white line bordered the kidney as it was a highly attenuating structure (Fig.10A). We could easily distinguish between the cortex and medulla in both longitudinal and transverse scanning plane. The renal cortex which appeared a gray granular outer area was uniform in the echogenicity and hyperechoic than the inner medulla (Fig.10A \& 10B). In the transverse ultrasonographic scanning plane, the common renal papilla had the same echogenicity of the medulla and projected toward the renal pelvis which was a hyperechoic V-shaped. The renal hilus could be observed as a hyperechoic area at the medial border of the kidney as it contained a high echogenic adipose tissue (Fig.10B).

\section{DISCUSSION}

Concerning the skeletal position of both kidneys, we observed that in male rabbit, the right kidney was related to thoracic cage as it extended from last thoracic to first lumbar vertebrae. However, there was no relation between the left kidney and the thoracic cage as it extended from second to third lumbar vertebrae. These results came in a line with those reported by Dimitrov and Chaprazov (2012) and Dorotea et al. (2016b) in rabbit. While in our results, the right kidney of female rabbit extended till second lumbar vertebra and was related dorsally to transverse process of the first, second and third lumbar vertebrae moreover, the left one extended till fourth lumbar vertebra.

Our observations were contrary to the position of the right kidney that reported by Hristov et al. (2006), Zotti et al. (2009) and Redrobe (2013) in rabbit, Hebel and Stromberg (1976) in rat and Veshkini et al. (2011) in Persian Squirrel, the later author found that, right kidney located between first and third lumbar vertebrae. While our results about the skeletal position of the left kidney were disagreed with the findings of Glukharev and Tovstoles (1961) and Dimitrov et al. (2012) in rabbits and Yoldas et al. (2014) in rats. In Persian Squirrel, Veshkini et al. (2011) stated that, left kidney was situated between third and fifth lumbar vertebrae.

In contrary to our observations that the kidneys and ureter could not be detected in plain radiographic image of rabbit without injection of contrast medium neither in lateral nor ventrodorsal view, Dimitrov and Chaprazov 
(2012) described that, the rabbit kidney could be distinguished by native radiographic examination as soft tissue structure with lower opacity from the surrounding soft tissue organs and bone structures.

Our study demonstrated that, the renal parenchyma was distinguished into a higher opacity medulla than the cortex in both lateral and ventrodorsal contrast radiographic examination. This was in partial agreement with Dimitrov and Chaprazov (2012) who observed that, the distinguishable borders between cortex and medulla were visualized in ventrodorsal nephrogram and not observed in lateral nephrogram.

The current study showed that, the cavity of renal pelvis and ureter could be observed as radiopaque finding as they filled with the radiopaque contrast medium. The renal hilus observed as low opacity depression filled with low density fat on the medial border in ventrodorsal radiograph. These findings went hand in hand with that found in rabbit by Dimitrov and Chaprazov (2012). They observed the contact between caudate lobe of liver and right kidney as striped finding with low opacity, while in our study we could poorly observe this contact due to superimposition of intestinal loops which contained radiolucent gases.In this context, the lateral border of both kidneys was related to the corresponding lateral abdominal wall. This result was conflicted with Dimitrov et al. (2012) in rabbit according to which, both kidneys did not touch the lateral abdominal walls and in partially agreed with the findings of Hristov et al. (2006) and Redrobe (2013) in rabbit who reported that, the left kidney touched the left abdominal wall. The medial border of right kidney was related to caudal vena cava, similar result was obtained by Al-Jebori et al. (2014) in rabbit.

The present work indicated that, the right kidney was related to duodenum with pancreas cranioventrally and ventrally and to the descending colon and cecum ventrally and caudoventrally. It was capped cranioventrally with right lateral and caudate lobes of liver under last intercostal space. Meanwhile, this was in partial agreement with the findings of Hristov et al. (2006) and Redrobe (2013) who observed that, rabbit right kidney was related caudally to descending duodenum. Also our observation was agreed with the findings of Al-Jebori et al. (2014) in rabbit who illustrated that, the right kidney was related ventrally to liver, pancreas and cecum. The descending duodenum and distal colon were seen medially to the right kidney (Banzato et al. 2014a) in rabbit.

Concerning the left kidney relations, it was related ventrally to jejunum and descending colon and was related cranioventrally to ascending duodenum. It was the same as the finding of Hristov et al. (2006), Redrobe (2013) and Al-Jebori et al. (2014) in rabbits. On the other hand, Olukole (2009) in African great cane rats and AlSamawy (2012) in albino rats, reported that the left kidney was related to stomach and spleen, while in our study we observed the ascending duodenum and jejunum separated the left kidney from stomach and spleen. This was due to species variations. In contrary with Banzato et al. (2014b) in rat, in our study, we reported that, there was no relation between reproductive system and both kidneys in both sexes.
The current investigation reported that, the renal cortex echogenicity was similar to or slightly less than the hepatic parenchyma which came on the same line with findings of Moarabiet al. (2011) in New Zealand white rabbit and Tolai Hare and Dimitrov (2012), Redrobe (2013) and Banzato et al. (2014a) in rabbit. WhileBanzato et al. (2014b) in rat and Pessoa et al. (2018) in Agoutis demonstrated that, the renal cortex was more in echogenicity than the liver parenchyma.

Regarding computed tomographic study of kidney, the perirenal fat appeared as a homogeneous hypodense structure around the hyperdense kidneys and also appeared at the site of contact between the right kidney and liver which had the same CT tissue density. Thus, we could differentiate between right kidney and liver by hypodense perirenal fat between them. These findings were simulated those results obtained by Yonkova et al. (2010) in New Zealand white rabbits.

Concerning ultrasonographic examination of kidney, the renal cortex appeared gray granular area, was homogeneous in echogenicity and hyperechoic than the medulla. These findings were in agreement with the findings of Moarabi et al. (2011) in New Zealand white rabbit and Tolai Hare, and in partial agreement with the findings of Dimitrov (2012) and Redrobe (2013) in rabbit who reported that, the renal cortex was heterogeneous in echogenicity and had multiple linear hyperechoic areas.

The renal medullary pyramid appeared as an echoic nearly circular areas represented the peripelvic columns which separated from each other by hyperechoic secondary septa projected from the hyperechoic centrally located main pelvic septum of renal pelvis. This description was also recorded by Dimitrov (2012) and Redrobe (2013) in rabbit. While, Moarabi et al. (2011) in New Zealand white rabbit and Tolai Hare, reported that, the centrally located hyperechoic area called the renal sinus and circular anechoic parts of medulla termed as medullary pyramids; Banzato et al. (2014a) in rabbit, stated that, the renal pelvis was not seen in both scanning plane and the centrally located hyperechoic part represented the renal sinus and Banzato et al. (2014b) in rat, observed that, the renal pelvis appeared as a centrally located anechoic crescent shaped band between renal sinus and renal crest in transverse scanning plane. The renal papilla appeared isoechoic to the medulla and projected toward the hyperechoic renal pelvis in transverse scanning plane. This observation was different from Banzato et al. (2014a) in rabbit who described that, the renal papilla was hyperechoic to the medulla in transverse scanning plane.

In this study, we could differentiate between cortex and medulla in both longitudinal and transverse scanning plane. This was similar to Banzato et al. (2014a) in rabbit, while in rat, Banzato et al. (2014b) reported that, there was no distinction between cortical and medullary echogenicity in longitudinal scanning plane. In the current study, the kidney appeared oval in longitudinal ultrasonographic scanning plane and nearly circular in transverse scanning plane. This partially agreed with the findings of Dimitrov (2012) and Redrobe (2013) in rabbit who observed the kidney as oval shaped finding in both longitudinal and transverse scanning plane. 
Regarding the mean weight of rabbit kidneys, there was no difference in the mean weight of both kidneys as it was $7.5 \pm 2.6 \mathrm{~g}$ and represented $0.24 \%$ from the mean body weight of rabbit. These results differed from Bolat et al. (2011), Al-Jebori et al. (2014) and Maurya et al. (2018). The later author reported that, the weight of right kidney was $1.39 \pm 0.17 \mathrm{~g}$ and the left one was $1.41 \pm 0.20 \mathrm{~g}$. On the other hand, Onyeanusi et al. (2007) reported that, the right and left kidneys of African giant rat were weighted $2.210 \pm 0.051 \mathrm{~g}$ and $2.00 \pm 0.055 \mathrm{~g}$, respectively and Olukole (2009) in African great cane rat, described that, the mean weight of the right and left kidneys were 3.57 \pm 0.22 and $3.46 \pm 0.19 \mathrm{~g}$, respectively. While in guinea pig, AlSharoott (2014) demonstrated that, the mean weight of both kidneys was $0.205 \pm 1.998 \mathrm{~g}$. These differences were due to species variations.

Concerning the mean length and width measurements of rabbit kidneys, the present study revealed the mean length of the right and left kidneys were $3.48 \pm 0.43$ and $3.55 \pm 0.44 \mathrm{~cm}$, while their mean width was $2.27 \pm 0.29$ and $2.3 \pm 0.29 \mathrm{~cm}$, respectively. This slightly differed from the findings of Bolat et al. (2011) in rabbit who observed that, the mean length of right and left kidneys was $3.21 \pm 0.60$ and $3.19 \pm 0.50 \mathrm{~cm}$, while their mean width was $2.15 \pm 0.33$ and $2.11 \pm 0.41 \mathrm{~cm}$, respectively. Our results also differed from the findings of Maurya et al. (2018) who reported that, the rabbit right and left kidneys length were $3.53 \pm 0.12$ and $3.88 \pm 0.07 \mathrm{~cm}$, while their mean width was $2.55 \pm 0.10$ and $2.65 \pm 0.08 \mathrm{~cm}$, respectively.

Regarding ultrasonographic measurements of rabbit kidney, our study revealed that, the mean length of the right and left kidneys was $3.52 \pm 0.35$ and $3.68 \pm 0.21 \mathrm{~cm}$, while their mean width was $2.46 \pm 0.40$ and $2.24 \pm 0.19 \mathrm{~cm}$, respectively. The mean depth of the right and left kidneys was $1.9 \pm 0.12$ and $1.92 \pm 0.16 \mathrm{~cm}$, respectively. This differed from the findings of Banzato et al. (2014a) in rabbit who observed that, length, width and depth of right kidney were $2.87 \pm 0.34,1.62 \pm 0.17$ and $1.66 \pm 0.14 \mathrm{~cm}$, respectively while that of left kidney were $2.86 \pm 0.33$, $1.72 \pm 0.19$ and $1.58 \pm 0.15 \mathrm{~cm}$, respectively. In our opinion, the difference in morphometric values of kidney in our study and the other authors in rabbit might be due to variation in age, breed, environmental factors and the instruments used to obtain the measurements.

\section{Conclusion}

The present results indicate that the using of gray scale ultrasonographic examination, radiographic examination and Computed Tomography scan (CT) beside the gross morphological examination is highly effective in detection of the shape, structure, position and relation of the kidney of rabbit.

\section{Author's Contribution}

All authors have done all the practical steps together as well as writing the paper and reviewing English, also reading and approving the final manuscript.

\section{Acknowledgement}

We thank all staff members in Department of Anatomy and Embryology, Faculty of Veterinary Medicine, Zagazig University, Egypt for helpful advice to finish this work. Paper extracted from M.V.Sc. thesis of Sahar Mohamed El-sayed Ibrahim.

\section{REFERENCES}

Al-Jebori JGA, Al-Badri AMS and Jassim BA, 2014. Study the anatomical and histomorphological description of the kidney in adult white rabbits female "New Zealand strain". World Journal of Pharmacy and Pharmaceutical Sciences 3 : 40-51.

Al-Kelaby WJA, Almhanna H, Hussein HJ, Abdulridha WM and Al-Shaibani SHW, 2018. Histological and biochemical evaluation of the efficiency of rabbit kidney after partial or radical nephrectomy. Biochemical and Cellular Archives 18: 2033-2042.

Al-Samawy ERM, 2012. Morphological and Histological study of the kidneys on the Albino rats. Al-Anbar Journal of Veterinary Science 5: 115-119.

Al-Sharoott HA, 2014. Morphological \&histological study of the kidney in guinea pig. International Journal of Recent Scientific Research 5: 1973-1976.

Banzato T, Bellini L, Contiero B, Selleri P and Zotti A, 2014a. Abdominal ultrasound features and reference values in 21 healthy rabbits. Veterinary Record 176: 101-108. https://doi.org/10.1136/vr.102657

Banzato T, Bellini L, Contiero B, Martin A, Balikçi S and Zotti A, 2014b. Abdominal anatomic features and reference values determined by use of ultrasonography in healthy common rats (Rattus norvegicus). American Journal of Veterinary Research 75: 67-76. https://doi.org/10.2460/ajvr.75.1.67.

Bolat D, Bahar S, Selcuk ML and Tipirdamaz S, 2011. Morphometric investigations of fresh and fixed rabbit kidney. Eurasian Journal of Veterinary Sciences 27: 149154.

Dal Monte M, Cammalleri M, Pecci V, Carmosino M, Procino G, Pini A, De Rosa M, Pavone V, Svelto M and Bagnoli P, 2019. Inhibiting the urokinase-type plasminogen activator receptor system recovers STZ-induced diabetic nephropathy. Journal of Cellular and Molecular Medicine 23: 1034-1049. https://doi.org/10.1111/jcmm.14004

Dimitrov RS, 2012. Ultrasound features of kidneys in the rabbit (Oryctolagus cuniculus). Veterinary World 5: 274-278. https://doi.org/10.5455/vetworld.2012.274-278

Dimitrov R and Chaprazov T, 2012. An anatomic and contrast enhancedradio-graphic investigation of the rabbit kidneys, ureters and urinary bladder. Revue de MédecineVétérinaire163: 469-474.

Dimitrov R, Kostov D, Stamatova K and Yordanova V, 2012.Anatomotopographical and morphological analysis of normal kidneys of rabbit (Oryctolagus cuniculus). Trakia Journal of Sciences 10: 79-84.

Dorotea SB, Banzato T, Bellini L, Contiero B and Zotti A 2016a. Kidney measures in the domestic rat: a radiographic study and a comparison to ultrasonographic reference values. Journal of Exotic Pet Medicine 25: 157-162. https://doi.org/10.1053/j.jepm.2016.03.011

Dorotea SB, Banzato T, Bellini L, Contiero B and Zotti A, 2016b. Radiographic anatomy of dwarf rabbit abdomen with normal measurements. Bulgarian Journal of Veterinary Medicine 19: 96-107. https://doi.org/10.15547/BJVM.911

El Sherif A, Mc Pherson SJ and Dixon AK, 1999. Spiral CT of the abdomen: increased diagnostic potential. European Journal of Radiology 31: 43-52 https://doi.org/10.1016/S0720-048X(98)00092-8

Fike JR, Druy EM, Zook BC, Davis DO, Thompson JE, Chaney $\mathrm{E}$ and Bradley EW, 1980. Canine anatomy as assessed by computerized tomography. American Journal of Veterinary Research 41: 1823-1832. 
Gavrilas E, Miro F, Blanco B, Lucena R, Ginel PJ and Novales M, 2016. Helical computed tomography-anatomy of the cat abdomen. Bulletin of University of Agricultural Sciences and Veterinary Medicine 73: 149-152. https://doi.org/ 10.15835/buasvmen-vm: 11937

Glukharev SAG and Tovstoles KF, 1961.A Procedure for intravenous urography in rabbits. Bulletin of Experimental Biology and Medicine51: 118-120.https://doi.org/10.1007/ BF01306894

Hebel R and Stromberg MW, 1976. Anatomy of the laboratory Rat. Williams \& Wilkins, Baltimore, USA, pp: 62-65.

Hristov H, Kostov D and Vladova D, 2006. Topographical anatomy of some abdominal organs in rabbits. Trakia Journal of Sciences 4: 7-10.

Lin HC, 2007. Dissociative anesthetics. In: Tranquilli WJ, Thurmon JC and Grimm KA. (eds): Lumb and Jones' Veterinary Anesthesia and Analgesia. $4^{\text {th }} \mathrm{Ed}$, WileyBlackwell Publishing, Ames, IA, USA, pp: 301-354.

Mantis P, 2008. Ultrasonography of the urinary and genital system of the dog and cat. Iranian Journal of Veterinary Surgery 3: 63-71.

Maurya H, Kumar T and Kumar S, 2018. Anatomical and physiological similarities of kidney in different experimental animals used for basic studies. Journal of Clinical \& Experimental Nephrology 3: 1-6. https://doi.org/10.21767/2472-5056.100060

Mazensky D and Flesarova S, 2017. Arrangement of renal arteries in guinea pig. The Anatomical Record 300: 556559.https://doi.org/10.1002/ar.23496

Makungu M, Plessis W, Barrows M, Groenewald HB and Koeppel KN,2016.Radiographic and ultrasonographic abdominal anatomy in captive ring-tailed lemurs (Lemur catta). Journal of Zoo and Wildlife Medicine 47: 573585.https://doi.org/10.1638/2015-0046.1

Moarabi A, Mosallanejad B, Ghadiri AR and Borujeni MP, 2011. Ultrasonographic evaluation of the urinary system in New Zealand white rabbit and Tolaihare. Veterinary Research Forum 2: 113-120.

Nomina Anatomica Veterinaria, 2017. International committee on veterinary gross anatomical Nomenclature. General assemble of the world association of veterinary anatomists, 6th Ed., Hannover (Germany), Columbia, MO (USA), Ghent (Belgium), Sapporo (Japan).

Novelline RA, Rhea JT, Rao PM and Stuk JL, 1999. Helical CT in emergency radiology. Radiology 213: 321-339. https://doi.org/10.1148/radiology.213.2.r99nv01321

Olukole SG, 2009. Morphometric analysis of the kidneys of the adult domesticated African great cane rat (Thryonomys swinderianus). European Journal of Anatomy 13: 117-120.

Onyeanusi BI, Adeniyi AA, Ayo JO and Nzalak JO, 2007. Morphometric studies on the kidneys of the African Giant Rat (Cricetomys Gambianus Waterhouse). Journal of Animal and Veterinary Advances 6: 1273-1276. https://doi.org/ javaa.2007.1273.1276

Ostrowska J, Kiełbowicz Z, Zaleska-Dorobisz U, Atamaniuk W, Pietsch-Fulbiszewska A and Kinda W, 2016. Resistive index (RI) obtained in renal interlobar arteries of normal dogs and cats by means of Doppler ultrasonography. Pakistan Veterinary Journal 36: 45-48.

Pessoa GT, Sousa FCA, Rodrigues RPS, Moura LS, Sanches MP, Ambrósio CE, Silva ABS and AlvesFR, 2018.
Abdominal B-mode and doppler ultrasonography of chemically restrained agouti (Dasyprocta prymnolopha Wagler, 1831). Pesquisa Veterinária Brasileira 38: 785-793. https://doi.org/10.1590/1678-5150-pvb-5433

Redrobe S, 2001. Imaging techniques in small mammals. Seminars in Avian and Exotic Pet Medicine 10: 187-197. https://doi.org/10.1053/saep.2001.24677

Redrobe S, 2013. Ultrasonography. In: Harcourt-Brown F and Chitty J (eds): Rabbit Surgery, Dentistry and Imaging. Ist Ed, British Small Animal Veterinary Association, pp: 94106.

Ibrahim SME, Ammar SMS, Omar AMEA, EL-Ghazali MH and Mohamed SKA, 2019. Some morphological studies on the kidney of Balady rabbit by using the recent techniques. A thesis of M.V.Sc. degree of Veterinary Medical Sciences Department of Anatomy \& Embryology. Faculty of Vet. Med. Zagazig University

Samii VF, Biller DS and Koblik PD, 1998. Normal crosssectional anatomy of the feline thorax and abdomen: comparison of computed tomography and cadaver anatomy. Veterinary Radiology \& Ultrasound 39: 504511.https://doi.org/10.1111/j.1740-8261.1998.tb01640.x.

Sánchez-Solís CN, Cuevas-Romero E, Munoz A, CervantesRodríguez M, Rodríguez-Antolín J and Nicolás-Toledo L, 2018. Morphometric changes and AQP2 expression in kidneys of young male rats exposed to chronic stress and a high-sucrose diet. Biomedicine \& Pharmacotherapy 105: 1098-1105.https://doi.org/10.1016/j.biopha.2018.06.086

Souza NP, Hard GC, Arnold LL, Foster KW, Pennington KL and Cohen SM, 2018. Epithelium lining rat renal papilla: Nomenclature and association with chronic progressive nephropathy (CPN). Toxicologic Pathology 46: 266-272. https://doi.org/10.1177/0192623318762694

Stickle RL and Hathcock JT, 1993. Interpretation of computed tomographic images. Veterinary Clinics of North America: Small Animal Practice 23: 417-435. https://doi.org/ 10.1016/s0195-5616(93)50035-9.

Thrall DE, 2017.Textbook of Veterinary Diagnostic Radiology, 7th Ed, Saunders Elsevier, St. Louis, pp: 693-695.

Veshkini A, Tavana M, Haghdost IS, Masouleh MN and Savojbolaghi SH, 2011. Excretory Urography by Subcutaneous Injection of Iodixanol in Persian Squirrel (Sciurus Anomalous). Pakistan Veterinary Journal 31: 17-22.

Wu J, Ge X and Fahy GM, 2003. Ultrarapid nonsuture mated cuff technique for renal transplantation in rabbits. Microsurgery 23: 369-373. https://doi.org/10.1002/micr. $\underline{10145}$

Yoldas A, Aydin A and Ilgun R, 2014. Macroscopic distribution of the renal artery and intrarenal arteries in mole rats (Spalax leucodon). Veterinarni Medicina 59: 382-387. https://doi.org/10.17221/7658-VETMED

Yonkova P, Dimitrov R, Toneva J and Zaprjanova D, 2010. A comparative study of cross-sectional anatomy and computed tomography of perirenal fat depots in New Zealand white rabbits. Trakia Journal of Sciences 8: 74-78.

Zotti A, Banzato T and Cozzi B, 2009. Cross-sectional anatomy of the rabbit neck and trunk: Comparison of computed tomography and cadaver anatomy. Research in Veterinary Science 87: 171-176. https://doi.org/10.1016/j.rvsc/2009. $\underline{02.003}$ 